\title{
Ectopic pregnancy: clinical features, management and complications
}

\author{
Tushar Tatyaba Palve, Rangan Bhattacharya*, Vijaydeepthi Matangi
}

Department of Obstetrics and Gynecology, Grant Medical College and JJ Group of Hospitals, Mumbai, Maharashtra, India

Received: 17 January 2018

Accepted: 28 February 2018

\section{*Correspondence:}

Dr. Rangan Bhattacharya,

E-mail: rbhattac@ rediffmail.com

Copyright: (C) the author(s), publisher and licensee Medip Academy. This is an open-access article distributed under the terms of the Creative Commons Attribution Non-Commercial License, which permits unrestricted non-commercial use, distribution, and reproduction in any medium, provided the original work is properly cited.

\section{ABSTRACT}

Background: An ectopic pregnancy (EP) occurs when a fertilized ovum implants outside the normal uterine cavity 1. Ectopic pregnancy (EP) is a condition presenting as a major health problem for women of childbearing age. 2 The incidence of EP varies with the population, but it has been accounted for 1-2\% of all reported pregnancies. EP is one of the few medical conditions that can be managed expectantly, medically or surgically. Surgical methods are still the mainstay in the management of EP, and in developed societies, laparoscopic surgery is currently the gold standard.

Methods: This is a retrospective observational study conducted in a tertiary care centre in Mumbai from November 2016 to November 2017. All patients diagnosed with ectopic pregnancy (by clinical examination, USG and/or B hCG) were included in the study. The aims and objectives of the study were to determine the demographic distribution, risk factors, clinical features, treatment modalities and complications in patients presenting with EP.

Results: The incidence of ectopic pregnancies in one year was $1.17 \%$. The commonest age of presentation of EP was between 35-40 years, most of the patients were Gravida 4 (28.57\%). Majority of patients presented at a gestational age between 6-8 weeks. Most patients (64.28\%) were found to have ruptured ectopic. $28.57 \%$ patients had a previous history of abortion. $14.28 \%$ of each EP were cornual and heterotopic as found intra-operatively. There was 1 interstitial and 1 scar ectopic pregnancy. The most common associated risk factor in these patients were a history of some form of pelvic surgeries in the past. Most of these patients presented with pain abdomen and were found to be anaemic and with a shock index (SBP/HR) of $>0.8$. $64.28 \%$ of cases were diagnosed by combination of TVS and serum BhCG levels. Two cases were managed medically, and obstetric hysterectomy was needed in the patient with ruptured scar ectopic gestation.

Conclusions: Ectopic pregnancy has a rising incidence in today's world. With the use of better diagnostic modalities, ectopic pregnancies can be detected early and treated appropriately. However, as a silent disease, it presents with subtle signs and symptoms and hence can be easily misdiagnosed. Also, because of its subtle presentations, patients often present late in the course of the disease, wherein management of the condition can be sometimes life - saving. But once diagnosed accurately, it needs prompt treatment. Treatment however is easy and patients respond wonderfully with both medical and surgical management.

Keywords: Amenorrhoea, BhCG, Ectopic pregnancy, Maternal mortality, Obstetric hysterectomy scar ectopic, Risk factors, Tubal pregnancy, Ultrasonography, Vaginal bleeding,

\section{INTRODUCTION}

An ectopic pregnancy (EP) occurs when a fertilized ovum implants outside the normal uterine cavity. ${ }^{1}$ Ectopic pregnancy (EP) is a condition presenting as a major health problem for women of childbearing age. ${ }^{2}$ The incidence of EP varies with the population, but it has been accounted for $1-2 \%$ of all reported pregnancies. ${ }^{3-4}$ 
Ectopic pregnancy (EP) is the leading cause of maternal death during the first trimester of pregnancy, accounting for approximately $10 \%$ of all pregnancy-related deaths. ${ }^{5}$ It has been shown to reduce subsequent fertility and increase the chances of subsequent EP. ${ }^{6}$ Over recent decades, there has been a rise in the incidence of EP.?

Approximately $1 / 100$ pregnancies are ectopic, with the conceptus usually implanting in the fallopian tube. ${ }^{8}$ Approximately $75.0 \%$ of deaths in the first trimester and $9.0 \%$ of all pregnancy-related deaths are due to EP. ${ }^{9}$

Almost all EPs occur in the fallopian tube (98.0\%), the ampulla is the most common site of implantation $(80.0 \%)$, followed by the isthmus $(12.0 \%)$, fimbria $(5.0 \%)$, cornua $(2.0 \%)$, and interstitial $(2.0-3.0 \%) .{ }^{10,11}$ The etiology of EP remains uncertain although a number of risk factors have been identified. ${ }^{12}$

A common factor for the development of such ectopics is the presence of a pathologic fallopian tube..$^{13} \mathrm{EP}$ may be asymptomatic, and the most common clinical presentation is first trimester vaginal bleeding and/or abdominal pain. ${ }^{14}$ Its diagnosis can be difficult. In current practice, in developed countries, diagnosis relies on a combination of ultrasound scanning and serial serum beta-human chorionic gonadotropin $(\beta-\mathrm{hCG})$ measurements. $^{15}$

EP is one of the few medical conditions that can be managed expectantly, medically or surgically. Surgical methods are still the mainstay in the management of EP, and in developed societies, laparoscopic surgery is currently the gold standard.

\section{METHODS}

This is a retrospective observational study conducted in a tertiary care centre in Mumbai from November 2016 to November 2017. All patients diagnosed with ectopic pregnancy (by clinical examination, USG and/or B hCG) were included in the study.

\section{Inclusion criteria}

- All patients presenting to the OPD/casualty with the diagnosis of an ectopic pregnancy, i.e. evidence of pregnancy at a site outside the uterine cavity with or without pregnancy within the cavity (diagnosed by radiological imaging with or without $\mathrm{B}$ hCG).

- $\quad$ Preeclampsia was taken as blood pressure $\geq 140 / 90$ $\mathrm{mmHg}$ or more on two occasions at least 6 hours apart with proteinuria as per international society for the study of hypertension in pregnancy.

\section{Exclusion criteria}

- Intrauterine pregnancies

The aims and objectives of the present study were to determine the demographic distribution of patients presenting with EP, determine the risk factors associated with the patients presenting with ectopic pregnancy, to describe the various locations and stats (ruptured/unruptured/tubal abortion) of ectopic pregnancies found in these patients, to assess the variety of clinical signs and symptoms of the patients presenting with EP, to describe the various modalities of treatment used in EP, and to describe the various complications associated with EP.

\section{RESULTS}

The incidence of ectopic pregnancies over one year was $1.17 \%$. The commonest age of presentation was between 35-40 years (Table 1).

Table 1: Age at presentation.

\begin{tabular}{|lll|}
\hline Age in years & Number of cases & Percentage \\
\hline Less than 20 & 1 & 7.14 \\
\hline $20-25$ & 3 & 21.42 \\
\hline $25-30$ & 3 & 21.42 \\
\hline $30-35$ & 1 & 7.14 \\
\hline $35-40$ & 4 & 28.57 \\
\hline$\geq 40$ & 2 & 14.28 \\
\hline
\end{tabular}

The youngest patient was 20years, and oldest was 48years. The mean age of presentation was 30.57 years. Most of the patients were Gravida 4 (28.57\%) (Table 2).

Table 2: Obstetric score at presentation.

\begin{tabular}{|lll|}
\hline Gravida & Number of cases & Percentage \\
\hline G1 & 4 & 28.57 \\
\hline G2 & 3 & 21.42 \\
\hline G3 & 2 & 14.28 \\
\hline G4 & 4 & 28.57 \\
\hline G5 & - & - \\
\hline G6 & 1 & 7.14 \\
\hline
\end{tabular}

Most patients presented at a gestational age between 6-8 weeks (Table 3).

Table 3: Gestational age at presentation.

\begin{tabular}{|lll|}
\hline $\begin{array}{l}\text { Gestational age } \\
\text { (weeks) }\end{array}$ & Number of cases & Percentage \\
\hline $4-6$ & 4 & 28.57 \\
\hline $6-8$ & 8 & 57.14 \\
\hline $8-10$ & 1 & 7.14 \\
\hline 10 & 1 & 7.14 \\
\hline
\end{tabular}

Longest gestational age at presentation was 10.3 weeks, location: Left tubal, Unruptured, and shortest gestational age: 4.5 weeks, location: interstitial, ruptured. Most patients $(64.28 \%)$ were found to have ruptured ectopic (Table 4$)$. While most patients $(64.28 \%)$ had previous living issues, $28.57 \%$ patients had a previous history of abortion (Table 5). One patient had a bad obstetric history 
(G4A3). 14.28\% of each EP were cornual and heterotopic as found intra-operatively.

Table 4: Intra-op (Ruptured/Unruptured).

\begin{tabular}{|lll|}
\hline & Number of cases & Percentage \\
\hline Ruptured ectopic & 5 & 35.71 \\
\hline Unruptured ectopic & 8 & 57.15 \\
\hline Tubal abortion & 1 & 7.14 \\
\hline
\end{tabular}

Table 5: Previous Obstetric History.

\begin{tabular}{|lll|}
\hline $\begin{array}{l}\text { Previous obstetric } \\
\text { history }\end{array}$ & $\begin{array}{l}\text { Number of } \\
\text { patients }\end{array}$ & Percentage \\
\hline Abortion & 4 & 28.57 \\
\hline Previous neonatal Death & 1 & 7.14 \\
\hline Live issues & 9 & 64.28 \\
\hline
\end{tabular}

There was 1 interstitial and 1 scar ectopic pregnancy. 8 other EP were found in other parts of the fallopian tube (Table 6).

Table 6: Location of ectopic.

\begin{tabular}{|c|c|c|}
\hline Location & $\begin{array}{l}\text { Number of } \\
\text { patients }\end{array}$ & Percentage \\
\hline Cornual & 2 & 14.28 \\
\hline Interstitial & 1 & 7.14 \\
\hline Other sites on tube & 8 & 57.14 \\
\hline Heterotopic & 2 & 14.28 \\
\hline Scar ectopic & 1 & 7.14 \\
\hline
\end{tabular}

$42.85 \%$ of patients have had some form of pelvic surgeries in the past. There were two cases $(14.28 \%)$ of EP after tubal ligation (Table 7).

Table 7: Risk factors.

\begin{tabular}{|lll|}
\hline Risk factor & $\begin{array}{l}\text { Number of } \\
\text { patients }\end{array}$ & Percentage \\
\hline Infertility & 1 & 7.14 \\
\hline Pelvic surgery & 6 & 42.85 \\
\hline History of tubal ligation & 2 & 14.28 \\
\hline None & 5 & 35.71 \\
\hline
\end{tabular}

The commonest presenting complaint was pain abdomen, seen in $71.43 \%$ of cases (Table 8 ).

Table 8: Presenting complaints.

\begin{tabular}{|lll|}
\hline Complaints & $\begin{array}{l}\text { Number of } \\
\text { patients }\end{array}$ & Percentage \\
\hline Pain & 10 & 71.43 \\
\hline Bleeding per vagina & - & - \\
\hline Pain and Bleeding P/V & 4 & 28.57 \\
\hline
\end{tabular}

Most patients presented with anaemia (haemoglobin between 7-9g \%) (Table 9). Lowest Haemoglobin was $6.3 \mathrm{~g} \%$ and highest was $11.8 \mathrm{~g} \%$, blood transfusion given in 6 patients. Shock index (HR/SBP) deranged in 11 cases (78.57\%) (Normal range 0.5-0.8) (Table 10).

Table 9: Haemoglobin at admission.

\begin{tabular}{|lll|}
\hline Haemoglobin $(\mathrm{g} \%)$ & $\begin{array}{l}\text { Number of } \\
\text { patients }\end{array}$ & Percentage \\
\hline$<7$ & 1 & 7.14 \\
\hline $7-9$ & 7 & 50 \\
\hline $9-11$ & 3 & 21.43 \\
\hline$>/=11$ & 3 & 21.43 \\
\hline
\end{tabular}

Table 10: Signs of Shock.

\begin{tabular}{|lll|}
\hline Signs & $\begin{array}{l}\text { Number of } \\
\text { patients }\end{array}$ & Percentage \\
\hline Pulse $\geq 100 / \mathrm{min}$ & 8 & 57.14 \\
\hline SBP $\leq 110 \mathrm{mmHg}$ & 12 & 85.71 \\
\hline
\end{tabular}

Previous h/o IUCD usage for $\geq 3$ years: 3 cases $(21.43 \%)$. $64.28 \%$ of cases were diagnosed by combination of TVS and serum BhCG levels (Table 11). Obstetric hysterectomy done in 1 patient (Table 12).

Table 11: Diagnostic modality.

\begin{tabular}{|lll|}
\hline Diagnostic modality & $\begin{array}{l}\text { Number of } \\
\text { cases }\end{array}$ & Percentage \\
\hline Only TVS & 5 & 35.71 \\
\hline TVS and B hCG & 9 & 64.28 \\
\hline
\end{tabular}

Table 12: Management Modalities.

\begin{tabular}{|lll|}
\hline Management modality & $\begin{array}{l}\text { Number of } \\
\text { cases }\end{array}$ & Percentage \\
\hline Surgical & 12 & 85.71 \\
\hline Medical & 2 & 14.29 \\
\hline
\end{tabular}

This patient was a 40-year-old lady G4P2L2A1, undergone LSCS twice in the past with 8 weeks of amenorrhoea, followed by spotting, urine pregnancy test positive (Serum B hCG 121883) with history of consumption of abortifacient, referred with an USG suggestive of a live right cornual ectopic pregnancy of size $2.6 \times 3.3 \times 3 \mathrm{~cm}$ with shaggy irregular walls, foetal pole and cardiac activity.

There was an evidence of surrounding echogenicity with stuck omentum showing confined rupture. On examination, patient was hemodynamically stable, but had minimal spotting per vagina and bilateral fornices were tender.

The decision of exploratory laparotomy was taken. Insitu, A G sac with placenta of size 4 x $3 \mathrm{~cm}$ approximately was seen along the previous LSCS scar site of the uterus with a rent of approximately $3 \times 3 \mathrm{~cm}$ at the scar site.

Resection of scar ectopic was done and attempts were made to close the rent, however failed. There was profuse 
bleeding from the site of the ectopic pregnancy, not controlled surgically, hence the decision of obstetric hysterectomy was made. Intra and post operatively patient was transfused with 3 units blood. Post-operative period was uneventful, B hCG levels falling to 115.1 on Day 5 post-operative. Patient was vitally stable and discharge after suture removal. After 1 week of discharge she was reviewed in the OPD with $\mathrm{S}$. BhCG levels $<2$ $\mathrm{IU} / \mathrm{ml}$. Histopathology report was suggestive of foci of decidua in sheets with degenerated chorionic villi.

Two cases were managed medically:

- 23 years old primigravida presented with pain abdomen and missed periods, urine pregnancy test positive and an USG suggestive of Right adnexal unruptured anechoic lesion. S. BhcG at presentation was 2943.22. Pt was treated with single dose methotrexate therapy. B hCG levels on D5 and D 7 post therapy was in falling trends and was negative after 3 weeks of therapy.

- 19-year-old primigravida, presented with an h/o amenorrhoea followed by spotting P/V. USG was suggestive of a well defined solid cystic lesion of size $1.5 \times 2 \times 2.1 \mathrm{~cm}$ with mild peripheral vascularity with no evidence of fetal pole or yolk sac. B HCG levels at presentation was 2780 . $\mathrm{Pt}$ was treated with single dose methotrexate therapy, after which B HCG levels fell to 143.53 and was negative after 1 week post therapy.

\section{DISCUSSION}

The incidence of ectopic gestation in our study was $1.17 \%$. The incidence of ectopic pregnancy is on a rise due to better diagnostic technologies, more use of IUCDs, increased incidence of PID and earlier diagnosis and management. In the developed world, between $1 \%$ and $2 \%$ of all reported pregnancies are ectopic pregnancies (comparable to the incidence of spontaneous twin pregnancy). ${ }^{16}$ The incidence is thought to be higher in developing countries, but specific numbers are unknown. Although the incidence in the developed world has remained relatively static in recent years, between 1972 and 1992 there was an estimated six-fold rise in the incidence of ectopic pregnancy. ${ }^{17}$

In this study, the commonest age group of presentation was between 35-40 years. Shafquat et al, showed the peak age of incidence as 26-30 years which was consistent with by Kumar et al, Igbarese et al. ${ }^{18-20}$ Bouyer's study showed that age plays an important role and increases the probability of exposure to other risk factors. $^{21}$ Aging may result in progressive loss of myoelectrical activity along the fallopian tubes. Age related changes in tubal function and tubal diverticula which increases with age, predispose patients to ectopic pregnancy. ${ }^{22}$
In this study, with regards to parity ectopic pregnancy was most frequently seen in multipara as compare to primi para. This is similar to the study by Shafquat et al. A study conducted at Department of the General Hospital "George Gennimatas" in Athens, Greece proved statistically significant positive association between ectopic pregnancy rupture and parity. ${ }^{23}$

The average gestational age at presentation, in this study was between 6-8 weeks. Mean gestational age at diagnosis of EP was 7.1 in the study conducted by Tahmina $S$ et al while Khaleeque et al, reported 6 weeks at diagnosis. ${ }^{24,25}$

The classical triad of amenorrhoea, pain and vaginal bleeding was seen in $28.57 \%$ patients in present study, as compared to Tahima $\mathrm{S}$ et al, wherein, this triad was seen in $40.3 \%$ cases. Other studies have reported this triad to be present in $28-95 \%$ women, clearly indicating that this is not a presenting feature in most cases. ${ }^{26}$

The incidence of ruptured ectopic in our study was $35.71 \%$ and Unruptured ectopic was $57.15 \%$. However, in a study conducted by Saxon D et al, $35 \%$ of women had an unruptured tubal pregnancy and $26 \%$ had a ruptured tube. ${ }^{27}$ Thus, the incidence of ruptured ectopic pregnancy is lower as compared to unruptured ectopic pregnancy. The reason for this is the early detection and management of cases due to better diagnostic modalities.

The incidence of interstitial EP was $7.14 \%$ in our study. This is similar to the incidence of interstitial EP in a study conducted by Fernandez et al., wherein the incidence interstitial EP was $3-11 \%{ }^{28}$

The incidence of heterotopic pregnancy in this study was $14.28 \%$. Heterotopic pregnancy was present in $4.2 \%$ of the ectopic pregnancies as per Yeasmin et al. ${ }^{29}$

The commonest predisposing factors in EP were tubectomy, spontaneous and induced abortion and history of infertility, prior history of Copper-T insertion and previous LSCS in this study. Similar risk factors were noted in various other studies. ${ }^{30}$

Shock index (HR/SBP) was deranged in $78.57 \%$ patients. In a study conducted by Sabina Yeasmin et al., almost half $(45 \%)$ cases of ectopic pregnancies were in a state of shock at admission. Studies have shown that in a natural conception cycles, heterotopic pregnancy is a rare event, occurring in $<1 / 30,000$ pregnancies. ${ }^{31}$

There has been one case of Caesarean scar ectopic in our study. Jurkovic et al. and Seow et al. have estimated that the prevalence of Caesarean scar pregnancy in their local population of women attending the early pregnancy assessment unit is 1:1800 and 1:2216 respectively. Its true incidence, however, has not been determined because so few cases have been reported in the literature: only 18 
cases appeared in the literature between 1978 and 2001 (Fylstra, 2002). ${ }^{32-34}$

Serum $\beta$-hCG and ultrasound were the diagnostic tools used for diagnosis of ectopic pregnancy in our study. Studies have shown that Ultrasonography should be the initial investigation for symptomatic women in their first trimester; when the results are indeterminate, the serum $\beta$ human chorionic gonadotropin concentration should be measured. Serial measurement of $\beta$-hCG and progesterone concentrations may be useful when the diagnosis remains unclear. The positive identification of a non-cystic adnexal mass with an empty uterus has a sensitivity of $84-90 \%$ and a specificity of $94-99 \%$ for the diagnosis of an ectopic gestation. In one large prospective study of 6621 patients, ectopic pregnancy was correctly diagnosed by TVS with a sensitivity of $90.9 \%$ and specificity of $99.9 \% .{ }^{35,36}$

Studies have shown that low haemoglobin and haematocrit values, may indicate an increased risk of tubal rupture. In the study conducted by Sabina Yeasmin et al $50.9 \%$ women were anaemic at the time of admission. This is similar to our study, wherein in $50 \%$ of cases had haemoglobin between $7-9 \mathrm{~g} \%$

In our study, two cases were managed medically. Both these cases were of primigravidae for whom medical management was considered for fertility sparing. Published data on women with an ectopic pregnancy medically managed were identified using a MEDLINE search from 1966 to 2001 . It was found that the overall success rate for women treated with methotrexate for an ectopic pregnancy was $89 \%{ }^{37}$

Surgical management was done in 12 cases which included total salpingectomy. Conservative surgery is not followed by an increased risk of repeat ectopic pregnancy, but by the risk of persistent ectopic pregnancy, which should be taken into account when deciding on the operative procedure. Canis $\mathrm{M}$ et al in their study concluded that the surgical treatment should be performed if the patient is hemodynamically unstable, $\beta$-hCG is $>10000 \mathrm{mIU} / \mathrm{mL}$, the ectopic pregnancy is $4 \mathrm{~cm}$ in diameter, if there is a medical contraindication to methotrexate, and if the patient may not be followed adequately after treatment. ${ }^{38}$

No maternal mortality found in our study, consistent with A. Abbas and H. Akram study. ${ }^{39}$ The 1997-1999 and 2003-2005 Confidential Enquiries into Maternal Deaths reports highlighted that most of the women who died from ectopic pregnancy were misdiagnosed in the primary care or accident and emergency settings. ${ }^{40}$

Funding: No funding sources Conflict of interest: None declared

Ethical approval: The study was approved by the Institutional Ethics Committee

\section{REFERENCES}

1. Berek JS. Early pregnancy loss and ectopic pregnancy. Berek and Novak's Gynecology. $14^{\text {th }}$ ed. Philadelphia, PA: Lippincott Williams \& Wilkins. 2007:533-34.

2. Zane SB, Kieke BA, Jr, Kendrick JS, Bruce C. Surveillance in a time of changing health care practices: Estimating ectopic pregnancy incidence in the United States. Matern Child Health J. 2002;6(4):227-36.

3. Shaw JL, Dey SK, Critchley HO, Horne AW. Current knowledge of the aetiology of human tubal ectopic pregnancy. Hum Reprod Update. 2010;16(4):432-44.

4. Vichnin M. Ectopic pregnancy in adolescents. Curr Opin Obstet Gynecol. 2008;20(5):475-8.

5. Farquhar CM. Ectopic pregnancy. Lancet. 2005;366 (9485):583-91.

6. Chow WH, Daling JR, Cates WJ, Greenberg RS. Epidemiology of ectopic pregnancy. Epidemiol Rev. 1987;9(1):70-94.

7. Walker JJ. Ectopic pregnancy. Clin Obstet Gynecol. 2007;50(1):89-99.

8. Bouyer J, Coste J, Fernandez H. Sites of ectopic pregnancy: a 10 year population-based study of 1800 cases. Hum Reprod. 2002;17:3224-30.

9. Marion LL, Meeks GR. Ectopic pregnancy: history, incidence, epidemiology, and risk factors. Clin Obstet Gynecol. 2012;55(2)376-86.

10. Bouyer J, Coste J, Fernandez H, Pouly JL, Job-Spira N. Sites of ectopic pregnancy: a 10 year populationbased study of 1800 cases. Hum Reprod. 2002;17(12):3224-30.

11. Stein JC, Wang R, Adler N, Boscardin J, Jacoby VL, Won G, et al. Emergency physician ultrasonography for evaluating patients at risk for ectopic pregnancy: a meta-analysis. Ann Emerg Med. 2010;56(6):67483.

12. Shaw JL, Dey SK, Critchley HO, Horne AW. Current knowledge of the aetiology of human tubal ectopic pregnancy. Hum Reprod Update. 2010;16(4):432-44.

13. Shetty P, Sharma N. Medical management of ectopic pregnancy. Apollo Med. 2012;9(3):198-201.

14. Alkatout I, Honemeyer U, Strauss A, Tinelli A, Malvasi A, Jonat W, et al. Clinical diagnosis and treatment of ectopic pregnancy. Obstet Gynecol Surv. 2013;68(8):571-81.

15. Varma R, Gupta J. Tubal ectopic pregnancy. BMJ Clin Evid. 2009:1406.

16. Goldner TE, Lawson HW, Xia Z, Atrash HK. Surveillance for ectopic pregnancy - United States, 1970-1989. MMWR CDC Surveill Summ. 1993;42:73-85.

17. Chang J, Elam-Evans LD, Berg CJ, Herndon J, Flowers L, Seed KA, et al. Pregnancy-related mortality surveillance - United States, 1991-1999. MMWR Surveill Summ. 2003;52(2):1-8. 
18. Shafquat T, Wahab S, Bawar S, Rahim R. Relation of age, parity and duration of subfertility as risk factors for ectopic pregnancy, Gomal J Med Sci. 2013;11:171-3.

19. Igbarese GO, Ebeigbe PN, Igbekoyi OF, Ajufoh BI. Ectopic pregnancy: an 11 years review in a tertiary centre in the Niger Delta. Trop Doct. 2005;35(3):175-7.

20. Majhi AK, Roy N, Karmakar KS, Banerjee PK. Ectopic pregnancy - an analysis of 180 cases. J Indian Med Assoc. 2007;105(6):308-12.

21. Sepilian VP, Wood E. Ectopic pregnancy. EMedicine Specialities- Obstet Gynaecol. 2010;1-5.

22. Menon S, Sammel MD, Vichnin M, Barnhart KT. Risk factors for ectopic pregnancy: a comparison between adult and adolescent women. J Paediatr Adolesc Gynecol. 2007;20(3):181-5.

23. Anorlu RI, Oluwole A, Abudu OO, Adebajo S. Risk factors for ectopic pregnancy in Lagos, Nigeria. Acta Obstet Gynecol Scand. 2005;84(2):184-8.

24. S Tahmina, Mary Daniel and Preethy Solomon. Clinical Analysis of Ectopic Pregnancies in a Tertiary Care Centre in Southern India: A Six-Year Retrospective Study. J Clin Diagn Res. 2016; 10(10):QC13-6.

25. Khaleeque F, Siddiqui RI, Jafarey SN. Ectopic pregnancies: A three year study. J-Pak Med Assoc. 2001;51(7):240-2

26. Abbar FA, Al-Wakeel M. A study of 45 cases of ectopic pregnancy. Int J Gynaecol Obstet Off Organ Int Fed Gynaecol Obstet. 1980;18(3):214-7.

27. Jani R, Munshi D, Jani S, Munshi S. Study of 50 cases of modern management of ectopic pregnancy. Int J Reprod Contracept Obstet Gynecol. 2014;3(2):374-9.

28. Fernandez H, Lelaidier C, Thouvenez V, Frydman R. The use of a pretherapeutic, predictive score to determine inclusion criteria for the non-surgical management of ectopic pregnancy. Hum Reprod. 1991;6(7):995-8.

29. Yeasmin MS, Uddin MJ, Hasan E. A Clinical Study of Ectopic Pregnancies in a Tertiary Care Hospital of Chittagong, Bangladesh. Chattagram Maa-O-Shishu Hospital Med College J. 2014: 28;13(3):1-4.

30. Gupta R, Porwal S, Swarnkar M, Sharma N, Maheshwari P. Incidence, trends and risk factors for
Ectopic Pregnancies in a tertiary care hospital of Rajasthan. JPBMS. 2012;16(07):1-3

31. Ludwig M, Kaisi M, Bauer O, Diedrich $\mathrm{K}$. Heterotopic pregnancy in a spontaneous cycle: do not forget about it! Eur J Obstet Gynecol Reprod Biol. 1999;87(1):91-93.

32. Jurkovic D, Hillaby K, Woelfer B, Lawrence A, Salim R and Elson CJ. First-trimester diagnosis and management of pregnancies implanted into the lower uterine segment Cesarean section scar. Ultrasound Obstet Gynecol. 2003;21(3):220-7.

33. Seow KM, Huang LW, Lin YH, Lin MY, Tsai YL and Hwang JL (2004) A Cesarean scar pregnancy: issues in management. Ultrasound Obstet Gynecol. 2004;23(3):247-53.

34. Fylstra DL. Ectopic pregnancy within a cesarean scar: a review. Obstet Gynecol Surv. 2002;57(8):537-43.

35. Kadar N, Romero R. HCG assays and ectopic pregnancy. Lancet. 1981;317(8231):1205-6.

36. Tay JI, Moore J, Walker JJ. Ectopic pregnancy. BMJ. 2000;320(7239):916-9.

37. Barnhart KT, Gosman G, Ashby R, Sammel M. The medical management of ectopic pregnancy: a metal analysis complaring single dose and multidose regimens. Obstet Gynecol. 2003;101(4):778-84.

38. Canis M, Savary D, Pouly JL, Wattiez A, Mage G. Ectopic pregnancy: criteria to decide between medical and conservative surgical treatment? J Gynecol Obstet Biol Reprod. 2003;32(7):S54-63.

39. Abbas A, Akram H. Ectopic Pregnancy; Audit at Maula Bakhsh Teaching Hospital Sargodha. Prof Med J. 2011;18(1):24-7.

40. Lewis GH. Saving Mothers' Lives: reviewing maternal deaths to make motherhood safer: 2006-08. The Eighth Report on Confidential Enquiries into Maternal Deaths in the United Kingdom. BJOG: Int J Obstet Gynaecol. 2011;118.

Cite this article as: Palve TT, Bhattacharya R, Matangi V. Ectopic pregnancy: clinical features, management and complications. Int J Reprod Contracept Obstet Gynecol 2018;7:1484-9. 